\title{
Moral Awareness: A Source of Improved Sustainable Performance
}

\author{
Mujahid Hussain ${ }^{1}$, Hamid Hassan ${ }^{1}$, Zafar Iqbal ${ }^{1}$, Amna Niazi ${ }^{2, *}$ and Yasuo Hoshino ${ }^{3}$ \\ 1 FAST School of Management Lahore, Lahore Campus, National University of Computer \& Emerging \\ Sciences, Lahore 54770, Pakistan; mujahid.hussain@nu.edu.pk (M.H.); hamid.hassan@nu.edu.pk (H.H.); \\ zafar.iqbal@nu.edu.pk (Z.I.) \\ 2 Humanities and Management Sciences Department, University of Engineering and Technology, \\ Lahore 54770, Pakistan \\ 3 Institute of Policy and Planning Sciences, University of Tsukuba, Tsukuba 305-8573, Japan; \\ hoshino2003@gmail.com \\ * Correspondence: amna.niazi@uet.edu.pk
}

Citation: Hussain, M.; Hassan, H.; Iqbal, Z.; Niazi, A.; Hoshino, Y. Moral Awareness: A Source of Improved Sustainable Performance. Sustainability 2021, 13, 13077. https:/ / doi.org/10.3390/su132313077

Academic Editor: Zabihollah Rezaee

Received: 16 September 2021

Accepted: 23 November 2021

Published: 25 November 2021

Publisher's Note: MDPI stays neutral with regard to jurisdictional claims in published maps and institutional affiliations.

Copyright: (c) 2021 by the authors. Licensee MDPI, Basel, Switzerland. This article is an open access article distributed under the terms and conditions of the Creative Commons Attribution (CC BY) license (https:// creativecommons.org/licenses/by/ $4.0 /)$.
Abstract: Despite the increasing realization of the significance of work ethics and moral awareness (MA) in businesses after mega scandals, such as those of Enron and Tyco, few studies have investigated the relationship between MA and employees' performance and the intermediate mechanisms that explain this relationship. This study proposes that as employees' work ethics are calibrated through ethical training, their MA increases, in turn affecting employees' job performance. This experimental study is aimed at investigating the impact of MA, increased through ethical training, on employees' job performance. Based on institutional theory, the multidimensional work ethic profile (MWEP) and strategic human resource management literature, it is hypothesized that MA of employees' is positively correlated with employees' performance and that this relationship is moderated by the age, gender and education level of the employees. In particular, the moral awareness component of ethical decision-making (EDM) models is considered as coextensive with work ethics in experimental design, and work ethics is depicted by a multidimensional work ethic profile (MWEP). The study used a sample of 100 employees of a golf club, divided into an experiment group and a control group with 50 employees each. The experiment group was subjected to an ethical training program focused on increasing MA. Employees' performance for both groups was evaluated based on eight sub-variables. The study concluded that increasing MA increases employees' performance, with no significant moderation effect of age, gender and education level on this relationship. The results of this study will go a long way in helping managers to increase the productivity of their employees through increased MA.

Keywords: moral awareness; institutional theory; ethical decision-making models; work ethics; strategic human resource management; multidimensional work ethic profile; employees' performance

\section{Introduction}

Productive work and purposive action are considered the hallmarks of the human race today [1,2]. However, perceptions about 'working for a living' have been at variance across time and space. According to Blaug and Spiegel (1972), the leading thinkers of ancient Greece looked down upon toilers and, although the Hebrew and Christian apostles laid much emphasis upon the dignity and worth of human labor, the larger context within which such teachings were interpreted deemed work as a punishment for the original sin of disobedience to God. It was not until the Protestant Reformation that work as such was re-imagined, in fact, glorified in the Western tradition [3]. The combined theological teachings of Luther and Calvin presented work as a duty to God, a discipline imposed on men by the will of God and a spiritual 'Calling of God' for each human being by the fruits of which one shall be ultimately recognized on the day of judgment [4]. In this vein, certain dimensions of work ethics were particularly extolled, which were the centrality of work in 
life, such as hard work, punctuality, thrift, worldly asceticism and the equality of all jobs in terms of spiritual dignity $[4,5]$.

The renowned 20th century German sociologist Max Weber (1930) gave an enduring life to the above archetype by theorizing that protestant work ethics acted as the vital force, the spirit behind capitalism, and, over time, gave birth to the modern industrialized West $[6,7]$. While a great deal of research has stemmed from Weber's thesis, only recently has it been argued that the components of work ethics need to be carefully examined and elucidated in order to provide a consistent framework for clarifying linkages with human and organizational behavior. For instance, Miller et al. (2002) developed and tested a new measure of work ethics, the MWEP. The MWEP is not a single unitary construct but a collection of seven conceptually distinct attitudes and beliefs relating to work activity in general. These are, first, the centrality of work in life, even if one is well off; second, self-reliance, i.e., avoiding dependence on other persons; third, belief in the virtues of hard work; fourth, leisure, i.e., balancing work with valuing the importance of non-work activities; fifth, morality/ethics of fair dealing with others; sixth, delaying gratification, i.e., future orientation; and seven, minimizing wasted time in life. Zhang et al. (2020) and Miller et al. (2002) construe MWEP as learned not innate; secular, i.e., not tied to any religious beliefs; and motivational in that it instigates work behavior [8,9].

One major critique of MWEP is that although there is considerable evidence in relation to the psychometric evaluation of MWEP, there is little evidence on the appropriateness of the metric as a measurement tool across cultures [10]. Arguably, Muslim, Hindu and Confucius civilizations have traditionally given meaning to work within their own philosophical systems. Nevertheless, in the footprints of Christianity, interpretations and revisions continue to date $[11,12]$. In any case, the notions of self-reliance, hard work, commitment and dedication, fair dealing, abiding contracts, shunning unethical methods of wealth accumulation and appreciating the scarcity of time are common denominators across major belief systems. Where they differ is in the metaphysical significance and social value attached to work [11,12]. Some studies in this vein indicate that, to a great extent, religious values and practices prevail in large parts of the non-western world; the theistic significance people attach to work can generate greater satisfaction and commitment to their employers $[13,14]$. In summary, at least in relation to the contemporary world, one may assume that MWEP is culturally universal, bearing potential for wider testing and broader exploration. Alternatively, one may assume that it is possible to situate or derive the components of MWEP from the diverse civilizational or cultural contexts that employees being studied may come from.

\subsection{From Work Ethics to Employees' Job Performance}

As indicated above, Miller et al. (2002) construe the components of the work ethic construct as learned phenomena and prone to acting as the loci of individual motivation, thereby reflected in one's work behavior [9]. In other words, one may postulate that if an employee's work ethics can be calibrated to an ethical standard, which, in this case, is composed of some or several elements of MWEP, in theory, the employee's job performance should improve all else being the same. However, the challenge lies in discovering how to calibrate an employee's work ethics to a given archetype, in this case, MWEP [15,16]. Here, a few assumptions are critical to our deliberations. First, we assume that an employee's work ethics can be regarded as a moral issue, whereas moral issues are those actions that have the potential to help or harm others or ourselves. Clearly, all components of MWEP meet this definition. Second, it is assumed that an employee is a moral agent, where a moral agent is a person who makes a moral decision. Third, we define a moral decision as a decision that is in keeping with the ethical principles of an employee. Once MWEP is considered as a reasonable representation of work ethics, work ethics is considered as a moral issue, and decisions regarding this issue are to be made by employees as moral agents; most models of EDM become relevant, potentially providing insight into how to calibrate an employee's work ethics to a given archetype [17]. 
What are EDM models? EDM models can be broadly classified into two categories, rationalist models and non-rationalist models [3]. The rationalist models are based on the cognitive developmental approach to ethics initiated by Kohlberg (2006) [18] and formalized into a prominent theoretical model by Rest (1986) [19]. The model was extended among others by Walker (2013) and Rogerson et al. (2011) [13,20]. These models emphasize that when faced with an ethical dilemma, moral agents engage in a rational, logical, deliberative cognitive process, evaluating and choosing among alternatives based on various ethical principles that might be in conflict with one another. The four distinct stages of this deliberative process are, first, becoming aware that there is a moral issue; second, exercising moral judgment; third, establishing moral intent or determination; and fourth, taking action based on intent, i.e., engaging in ethical behavior. During this process, a range of individual and external factors may influence each stage of decision making. Among the individual influences on ethical decision making are education level and professional experience, national and cultural characteristics, cognitive moral development, personal values and integrity and moral imagination [5].

When it comes to the non-rationalist models of EDM, intuition and/or emotion or sentiments take center stage in forming moral judgment, followed by a retroactive process of rationalizing previous moral judgments [5]. Sonenshein's (2007) three-stage sensemaking-intuition model (SIM) is a case in point. Individual decision makers engage in issue construction, intuitive judgment and explanation and justification, the lines between these three phases being blurry, permitting overlapping feedback loops and simultaneous processing [21]. Importantly, while individual and collective factors influence issue construction, as well as intuitive judgment, the latter is not the result of a deliberative process but rather a fast, instantaneous, effortless appraisal of a situation based on intuition or emotion. In contrast to this largely unconscious behavior, the third and the final phase of the SIM, viz., explanation and justification, involves moral reasoning and justification of prior decision making in accordance with one's moral beliefs and value system.

Can the above EDM models provide insight into how to calibrate an employee's work ethics to a given archetype? There may be many a slip between the cup and the lip. As researchers contend, although both the rationalist and the non-rationalist models of EDM increase our understanding of moral behavior, they do not really explicate the necessary steps to enhance MA and/or intuitional or emotional sense-making in individuals so as to promote EDM [17]. This is precisely where multiple scholars were instructive [20,21]. They re-synthesized the major components of the EDM models into an integrated EDM (I-EDM) retaining all the four stages of Rest (1986), admitting individual and situational influences on decision making, and accepting the role of cognitive, emotivism, intuitionist and ratiobased justifications at the ethical judgment stage [19]. However, there is a twist. Other researchers have classified the large number of variables as individual influences affecting EDM, and Schwartz (2016) collates them into a single construct called the moral capacity of an individual. Included among the components of moral capacity are demographic variables, personality or psychological variables and ethical experience. In the words of Schwartz (2016), moral capacity is then defined as the ability of an individual to avoid moral temptations, engage in the proper resolution of ethical dilemmas and ultimately engage in ethical behavior $[22,23]$. This formulation rightly puts the horse before the cart in that instead of individual factors influencing each stage of the EDM process-awareness, judgment, intention and action-they instead affect an individual's moral capacity that, in turn, influences other stages of EDM. Moral attentiveness, moral mindfulness, moral imagination and moral framing increase MA, while moral disengagement, ethical fading, ethical blindness, non-moral framing and moral myopia create a lack of MA. The implications are that some new vistas open up in terms of explicating the necessary steps to enhance MA and/or intuitional or emotional sense-making, addressing the critique of above [24]. Briefly, teaching and training focused on the potential ethical implications of an array of ethical dilemmas can likely enhance subjects' MA. Similarly, learning ethical theory can sharpen moral reasoning, thereby improving moral judgment. 


\subsection{Hypotheses Development}

It is plausible now to pull the threads together and relate the above literature to the problem at hand. Briefly, if work ethics is a 'learned' moral construct amenable to 'motivation', employees are moral agents engaged in ethical decision making on work ethics, EDM is influenced by both individual moral capacity and a range of situational factors, and job performance is one of the outcomes of better work ethics, then, keeping all else constant, improving work ethics should positively affect job performance via increased MA. This, precisely, is the relationship that we tested in the research conducted at Lahore (Pakistan) Garrison Golf and Country Club. Taking MWEP as the surrogate for work ethics, we designed start-of-day motivational talks that focused on the normative significance of MWEP within the local cultural repertoire, and as a follow-up, we undertook detailed measures of employees' job performance as perceived by clients. The start-of-day motivational talks included topics such as one's responsibility toward God, employers, society and fellow workers, the benefits of honesty, the benefits of punctuality, the benefits of cleanliness, the importance of hard work, the importance of jobs and other similar topics. EDM models are taken as the starting point for examining the relationship between MA and employees' performance, keeping all other influences unchanged. The MA component of EDM models is considered as coextensive with work ethics in experimental design, whereas work ethics is depicted by MWEP.

Despite the increasing realization of the significance of work ethics and MA in businesses after mega scandals, such as Enron and Tyco, few studies have investigated the relationship between MA and employees' performance and the intermediate mechanisms that explain this relationship. The main aim of this study is to fill this gap in the literature by investigating the relationship between MA and employees' job performance, keeping all other influences unchanged. EDM models are taken as the starting point for examining this relationship. Another proposition here is that education and training on work ethics would enhance MA of the subjects, stimulating employees' job performance. For the empirical settings, MA is taken as a factor coextensive with education and training and considered as an independent variable to examine its impact on the dependent variable of employees' job performance. The financial incentives available to employees at a given time are kept unchanged as a control variable. The dependent variable of employee performance is comprehensively measured through eight sub-components, i.e., the quantity of output, the timeliness of the work carried out, clients' satisfaction, appearance and personal cleanliness, punctuality, the quality of the work carried out, honesty at the workplace and team spirit. This experimental study is aimed at investigating the impact of MA (increased through ethical training) on employees' job performance. Based on institutional theory, the multidimensional work ethic profile (MWEP) and strategic human resource management literature, it is hypothesized that MA of employees' is positively correlated with employees' performance. Many researchers recommend that age, education level and gender are important demographic variables that may improve the understanding of the relationship between MA and employees' performance, because they affect behavioral intention, adoption and the acceptance of training $[25,26]$. We therefore hypothesize that the relationship between MA and employees' performance is moderated by age, gender and the education level of the employees. In particular, the moral awareness component of ethical decision-making (EDM) models is considered as coextensive with work ethics in experimental design, whereas work ethics is depicted by a multidimensional work ethic profile (MWEP). The study used a sample of 100 employees of a Golf Club, divided into an experiment group and a control group of 50 employees each. The experiment group was subjected to an ethical training program focused on increasing MA. Employees' performance for both the experiment and control groups was evaluated based on eight sub-variables. The study concluded that increasing MA increases employees' performance, with no significant moderation effect of age, gender and education level on this relationship. The results of this study will go a long way in helping managers to increase the 
productivity of their employees through increased MA. The research question is presented by the following hypotheses:

Hypothesis 1: Improvement in MA positively impacts employees' job performance.

Hypothesis 2A: The age of the employees has a moderating effect on the causal relation between $M A$ and the employees' job performance.

Hypothesis 2B: The education level of the employees has a moderating effect on the causal relation between MA and the employees' job performance.

Hypothesis 2C: The gender of the employees has a moderating effect on the causal relation between MA and the employees' job performance. Figure 1 below represents our study model.

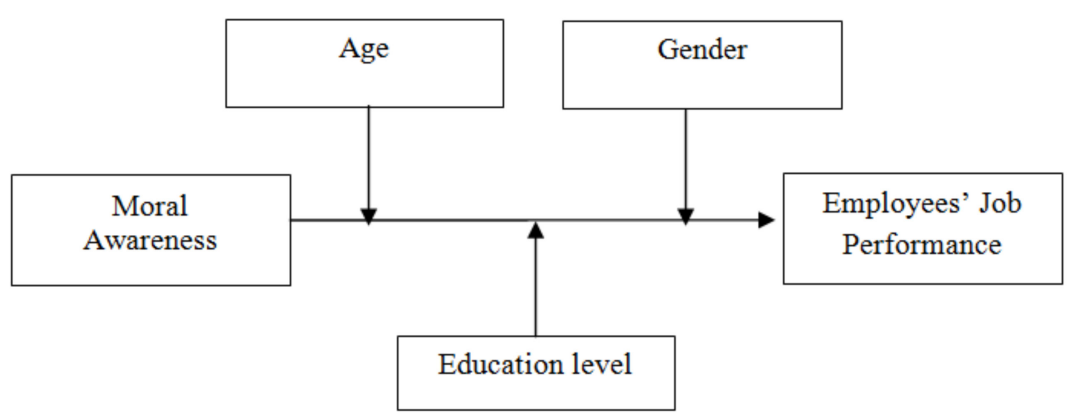

Figure 1. Theoretical framework.

\section{Materials and Methods}

\subsection{Design of Experiment}

Taking a lead from institutional theory, MWEP and EDM models, this longitudinal and experimental study was divided into five phases with a duration of one month each (total of 5 months) as under:

Phase 1: Combined w/o motivation evaluation. During this phase, all 100 employees continued working in the usual routine to check the evaluation procedure and to ascertain the average score of employees' performance.

Phase 2: Group-wise evaluation without motivation. During this phase, the employees were divided into two groups of 50 each without any other action or instruction. During this stage, the score of employees' performance was expected to generally remain the same as that of phase 1 if there was no Hawthorne effect.

Phase 3: Group-wise evaluation with motivation. During this phase, the experiment group was subjected to start-of-day motivational talks that focused on the normative significance of MWEP within the local cultural repertoire. The score of employees' performance of the experiment group was expected to gradually increase from 5 to 9 , whereas the score of the control group was expected to remain generally unchanged. This phase was aimed at measuring the impact of increasing MA due to the start-of-day motivational talks as explained by the EDM models. In light of institutional theory, norms, a social structure, the rules of governance, policies etc., can shape action and thinking in organizations $[7,25]$. The increased MA as a result of ethical training was expected to shape the actions and thinking of the employees.

Phase 4: Group-wise evaluation without motivation. During this phase, the start-ofday motivational talks were discontinued. The score of employees' performance of the experiment group was expected to start falling, and the score of the control group was expected to generally remain the same throughout the month. This phase was aimed at determining whether the score of employees' performance of the experiment group falls when there is no start-of-day motivational talks. 
Phase 5: Combined w/o motivation evaluation. During this phase, the control group and the experiment groups were abolished, but the evaluation continued as per normal practice. The score of employees' performance was expected to keep falling, though slowly as compared to phase 4 . Phase 5 , similar to phase 4 , was aimed at seeing if the score of employees' performance of the experiment group continued to fall when there were no start-of-day motivational talks and to check for any Hawthorne effect.

The venue of the experiment was Lahore Garrison Golf and Country Club, Pakistan. This setup was selected for the experiment because of its diverse human resource and the willingness of the club management to allow this experiment to be conducted. Another reason for selecting this venue was the ease of undertaking the experiment. The employees of the club assemble together as a routine for attendance etc., and as such, it was possible to conduct ethical training without disturbing their functioning. We requested the services of a team of five evaluators, who are veteran players of Lahore Garrison Golf and Country Club, for evaluation of the employees' job performance. The rating scale (1-10) was used for employees' evaluation, with $1=$ low and $10=$ high. Most of the sub-variables used for employees' evaluation were taken from the standard employee evaluation system of the club. This evaluation system is quite mature, reliable and is considered successful for employees' evaluation, and it has been used by the club management for the last couple of decades. However, a pilot study was also conducted to confirm the reliability of the standard evaluation system using twenty (20) employees of the club as a random sample. The study concluded that the system of evaluation being used by the Lahore Garrison Golf and Country Club was reliable, with a scale reliability coefficient of 0.72 , and it was accepted as such.

A sample of 100 employees for this study was divided into two groups of 50 employees each. The first group, i.e., the experiment group, was subjected to a moral education program on a daily basis. The program consisted of up to $20 \mathrm{~min}$ of lectures designed to reinforce work ethics approximated by MWEP. The schedule of the other group, i.e., the control group, was unchanged. MA reinforcement to the experiment group was provided by the researcher, volunteers from the senior management of the club and senior golf players.

\subsection{Demographic Data}

Employees' of Lahore Garrison Golf and Country Club working on fairways, tees and greens were taken as the sampling frame for this study. The sample for this study consisted of 100 randomly picked employees from this population. Out of these, two employees left their job during the first two months and another employee proceeded on sick leave for one month during the fourth month of the study. The sample was therefore reduced to 97 employees $(n=97)$, out of which 78 employees $(80 \%)$ were male and 19 employees $(20 \%)$ were female; the ratio between males and females for both the experiment and control groups was almost the same. In terms of age, 78 employees $(80 \%)$ were between 31 and 50 years and 18 employees (19\%) were between 18 and 30 years of age, with one odd outlier. Regarding educational level, 73 employees (75\%) had a middle level (8th grade) certificate, while the remaining 24 employees (25\%) were either without or had a less than 8th grade certification. Sixty-three employees $(65 \%)$ had more than 10 years of tenure on their jobs at Lahore Garrison Golf and Country Club, and the remaining (35\%) had a less than 10 years tenure. Seventy-one employees (73.2\%) were Muslims, and 26 employees $(26.8 \%)$ were Christians. The participants in the sample included $75(77 \%)$ laborers and $22(23 \%)$ service workers (e.g., shop assistants, waiters and barmen). Participants worked an average of $48 \mathrm{~h}$ per week. The details of the demographic characteristics are presented in Table 1. 
Table 1. Demographic characteristics of respondents.

\begin{tabular}{cccc}
\hline & Demographics & Frequency & Percentage \\
\hline Gender & Male & 78 & 80 \\
Age & Female & 19 & 20 \\
& 18-30 years & 18 & 19 \\
& 31-50 years & 78 & 80 \\
Length of service & 50 years and above & 1 & 1 \\
& 0 up to 10 years & 63 & 65 \\
Monthly income & More than 10 years & 34 & 35 \\
& Rs. 0 to Rs. 14,999 & 10 & 10 \\
& Rs. 15,000 to Rs. 20,000 & 61 & 63 \\
& Rs. 20,001 and above & 26 & 27 \\
\hline
\end{tabular}

\subsection{Empirical Settings}

We ran random effects ordered logistic regression to determine the impact of independent variables on dependent variables. The same test was also applied to investigate the moderation effect of education level, age and gender on the correlation between increasing MA and the employees' job performance. The applied regression test is helpful for data where variables have more than two categories (1-10 in our case) with meaningful sequential order (statistically it is polytomous ordinal). Keeping parsimony in view, step-by-step random effects ordered logistic regression analysis was used to explain the proportion of variance in the sub-variables of employees' job performance, which is explained by the increasing MA of employees. The $p$-values of the likelihood ratio test for all the subvariables of employees' job performance also show that, in this case, random effects ordered logistic regression is a preferred option over standard ordered logistic regression. The age, gender and education level of employees were tested for their moderation effect on the sub-variables of employees' job performance. Finally, the scores of phase 1 and the scores of phase 5 were compared to see if there was any Hawthorne effect. The value of the scale reliability coefficient (0.72) for the employees' job performance questionnaire in the pilot study means that it may be accepted as such. The reliability is further confirmed by the cut points obtained after applying the ordered logistic regression model, because all nine cut points of all the sub-variables measuring employees' job performance, except team spirit and appearance, are significantly different from each other. This means that all the categories of the rating scale of the evaluation tool are relevant, and there is no need to eliminate any of the parameters of the employees' construct. The overall model has a scale reliability coefficient of 0.844 , which shows that the variable measurement scale for all the variables is usable, and a specified domain is adequately sampled by the items measuring the construct of interest. All the dependent sub-variables have Prob $>$ chi2 value $<0.05$, which means that the coefficients for these variables are different than the zero and can explain the variance in the sub-variables of employees' job performance, thus adding to the reliability of the research model. The results of the tests are discussed in the succeeding paragraphs.

\subsection{Reliability Test and Descriptive Statistics}

The average inter-item covariance (0.987) and the scale reliability coefficient $(0.844)$ confirm the reliability of the study model. There are 1440 valid observations for the experiment group and 1470 valid observations (out of a total of 2910) for the control group. Eight sub-variables constituting the employees' job performance construct were measured, with a total of 97 cases for phase 1. A similar number for the rest of the 4 phases demonstrates the comprehensiveness of the study. The evidence supporting $\mathrm{H} 1$ is visible from the descriptive statistics. There is a visible difference among the means of all the sub-variables of employees' job performance of the control group and the experiment group in the third phase. Other statistical tests draw precise conclusions as explained in the subsequent paragraphs. The descriptive statistics of the study are presented in Table 2. 
Table 2. Descriptive statistics.

\begin{tabular}{ccccccccc}
\hline & \multicolumn{4}{c}{ Experiment Group } & \multicolumn{3}{c}{ Control Group } \\
\hline Variables & $\mathbf{N}$ & Minimum & Maximum & Mean & $\mathbf{N}$ & Minimum & Maximum & Mean \\
\hline AGE & 1440 & 22 & 59 & 38.87 & 1470 & 19 & 58 & 38.96 \\
QUANT & 1440 & 1 & 8 & 5.43 & 1470 & 2 & 10 & 6.54 \\
Time & 1440 & 1 & 9 & 5.02 & 1470 & 2 & 10 & 5.98 \\
SATIS & 1440 & 1 & 8 & 4.50 & 1470 & 2 & 10 & 6.08 \\
Appea & 1440 & 1 & 9 & 4.65 & 1470 & 2 & 10 & 5.13 \\
Punct & 1440 & 1 & 9 & 4.97 & 1470 & 2 & 10 & 5.94 \\
Qual & 1440 & 1 & 9 & 5.27 & 1470 & 2 & 10 & 6.32 \\
Honest & 1440 & 1 & 9 & 5.26 & 1470 & 2 & 10 & 6.53 \\
Teamsp & 1440 & 1 & 10 & 5.89 & 1470 & 2 & 10 & 7.59 \\
MA & 1440 & 4 & 6 & 5.083 & 1470 & 3.0 & 9.91 & 7.167 \\
Valid N (2910) & 1440 & & & & 1470 & & \\
\hline
\end{tabular}

Key: QUANT $=$ quantity of output, Time $=$ timeliness of the work carried out, SATIS= players' satisfaction, Appea $=$ appearance and personal cleanliness, Punct $=$ punctuality about work timings, Qual = quality of work carried out, Honest $=$ honesty at workplace, Teamsp $=$ team spirit among employees.

\subsection{Cut Points}

All nine cut points of the parameters measuring the employees' job performance construct, except team spirit (Teamsp) and appearance (Appea), are significantly different from each other. This means that all the categories are relevant, and there is no need to eliminate any category measuring the sub-variables of the employees' job performance construct. Cut points 3 and 4 for Teamsp with $p$-values equal to 0.064 and 0.122 and for Appea with $p$-values equal to 0.068 and 0.401 , respectively, are not significantly different. We could eliminate these cut points, but since they are significantly different for all other sub-variables, we therefore retained them in the evaluation tool as shown in Table 3.

Table 3. $p$-Values for cut points.

\begin{tabular}{ccccccccc}
\hline \multirow{2}{*}{ Cut Points } & \multicolumn{9}{c}{$p>$ IZ I } \\
\cline { 2 - 9 } & QUANT & Time & Satisfac & Appea & Punct & Qual & Honest & Teamsp \\
\hline / cut 1 & 0.636 & 0.439 & 0.001 & 0.000 & 0.388 & 0.046 & 0.088 & 0.000 \\
/ cut 2 & 0.005 & 0.000 & 0.000 & 0.001 & 0.016 & 0.000 & 0.002 & 0.002 \\
/ cut 3 & 0.000 & 0.000 & 0.000 & 0.068 & 0.000 & 0.000 & 0.000 & 0.641 \\
/ cut 4 & 0.000 & 0.000 & 0.000 & 0.401 & 0.000 & 0.000 & 0.000 & 0.122 \\
/ cut 5 & 0.000 & 0.000 & 0.000 & 0.001 & 0.000 & 0.000 & 0.000 \\
/ cut 6 & 0.000 & 0.000 & 0.000 & 0.000 & 0.000 & 0.000 & 0.000 & 0.000 \\
/ cut 7 & 0.000 & 0.000 & 0.000 & 0.000 & 0.000 & 0.000 & 0.000 \\
/ cut 8 & 0.000 & 0.000 & 0.000 & 0.000 & 0.000 & 0.000 & 0.000 & 0.000 \\
/ cut 9 & 0.000 & 0.000 & 0.000 & 0.000 & 0.000 & 0.000 & 0.000 & 0.000 \\
\hline
\end{tabular}

\section{Results}

\subsection{Regression Analysis}

The impact of MA on all the sub-variables of the employees' construct is significant with $p$-value $<0.05$. Employee's presence in the experiment or control group influences their performance parameters with $p$-value $<0.05$, except player's satisfaction, where $p$ value is 0.07 . The moderating variables age and education level have no significant impact on the parameters of the employees' construct. The same is the case with the moderation effect of gender (GEND) with $p$-value $>0.05$, except timeliness in the case of females with $p$-value $<0.05$, which means that females also improve upon the timely completion of their assignments due to increasing MA. The value of the odds ratio (2.48) for MA related to quantity (QUANT) is the highest and that (1.07) related to Appea is the lowest. This means that the odds of the highest performance category in QUANT and Appea for one unit increase in MA versus the combined remaining categories are 2.48 and 1.07, respectively, if 
all other variables used in the model are constant. Similarly, to move from the control group to the experiment group, the odds of the highest performance category in QUANT versus the combined remaining categories are 2.57 greater (highest) and 0.54 greater (lowest) in the case of Teamsp if all other variables in the model are constant. The regression results are presented in Table 4.

Table 4. Regression results.

\begin{tabular}{|c|c|c|c|c|}
\hline \multicolumn{5}{|c|}{ Prob $>$ chi $2=0.0000$} \\
\hline Dependent Variable & Independent Variable & Odds Ratio & $\mathbf{Z}$ & $p>$ IZ I \\
\hline \multirow{5}{*}{ QUANT } & AGE & 1.001806 & 0.28 & 0.778 \\
\hline & MA & 2.480024 & 8.33 & 0.000 \\
\hline & GROUP & 2.571099 & 6.02 & 0.000 \\
\hline & EDU & 0.9736488 & -0.47 & 0.636 \\
\hline & GEND & 0.7968281 & -1.53 & 0.126 \\
\hline \multirow{5}{*}{ Time } & AGE & 1.001021 & 0.16 & 0.869 \\
\hline & MA & 2.204187 & 8.54 & 0.000 \\
\hline & GROUP & 1.982501 & 4.91 & 0.000 \\
\hline & EDU & 1.017743 & 0.45 & 0.656 \\
\hline & GEND & 0.7234098 & -2.39 & 0.017 \\
\hline \multirow{5}{*}{ Satisfac } & AGE & 0.998586 & -0.22 & 0.823 \\
\hline & MA & 2.419179 & 8.84 & 0.000 \\
\hline & GROUP & 1.21362 & 1.84 & 0.066 \\
\hline & EDU & 1.305012 & 1.59 & 0.113 \\
\hline & GEND & 1.03302 & 0.74 & 0.460 \\
\hline \multirow{5}{*}{ Appea } & AGE & 1.005818 & 1.52 & 0.128 \\
\hline & MA & 1.074139 & 2.54 & 0.011 \\
\hline & GROUP & 0.7882322 & -2.22 & 0.027 \\
\hline & EDU & 0.9821397 & -0.62 & 0.536 \\
\hline & GEND & 0.9536755 & -0.58 & 0.564 \\
\hline \multirow{5}{*}{ Punct } & AGE & 1.005099 & 1.20 & 0.230 \\
\hline & MA & 1.754599 & 6.25 & 0.000 \\
\hline & GROUP & 1.515761 & 3.01 & 0.003 \\
\hline & EDU & 0.9602871 & -1.35 & 0.176 \\
\hline & GEND & 0.8629974 & -1.41 & 0.158 \\
\hline \multirow{5}{*}{ QUAL } & AGE & 0.9998332 & -0.03 & 0.978 \\
\hline & MA & 1.219773 & 7.37 & 0.000 \\
\hline & GROUP & 2.125371 & 4.92 & 0.000 \\
\hline & EDU & 0.9753081 & -0.57 & 0.571 \\
\hline & GEND & 0.8898157 & -0.84 & 0.399 \\
\hline \multirow{5}{*}{ Honest } & AGE & 1.006974 & 1.04 & 0.299 \\
\hline & MA & 1.499688 & 8.03 & 0.000 \\
\hline & GROUP & 1.83598 & 3.97 & 0.000 \\
\hline & EDU & 0.9939107 & -0.11 & 0.916 \\
\hline & GEND & 0.9038689 & -0.65 & 0.516 \\
\hline \multirow{5}{*}{ Teamsp } & AGE & 1.004645 & 0.93 & 0.353 \\
\hline & $\mathrm{MA}$ & 1.72022 & 7.83 & 0.000 \\
\hline & GROUP & 0.5346275 & -3.97 & 0.000 \\
\hline & EDU & 0.9870845 & -0.27 & 0.784 \\
\hline & GEND & 0.8748207 & -1.31 & 0.192 \\
\hline
\end{tabular}

Key: EDU = education level, GEND = gender.

\subsection{Hawthorne Effect}

The first three phases of the experiment focused on studying the effect of MA on employees' job performance, and during the fourth and fifth phases, we reversed the process to improve the validity of the results and check if there was any Hawthorne effect. The researchers compared the score at the end of phase 5 with the score on day 1 of phase 1 to see if there was any sign of the Hawthorne effect. The performance of the control group was monitored throughout the whole experiment, i.e., throughout all of the five 
phases, checking the spillover effect. The results of the one-sample statistics are presented in Table 5.

Table 5. One-sample statistics.

\begin{tabular}{ccccc}
\hline & N & Mean & Std. Deviation & Std. Error Mean \\
\hline Score First Day Phase1 & 900 & 4.8975 & 1.48433 & 0.04948 \\
Score Last Day Phase5 & 900 & 5.07525 & 0.72757 & 0.02425 \\
\hline
\end{tabular}

\section{Discussion}

Past studies investigating the relationship between corporate ethics and firm performance have focused on externally oriented perspectives, such as relationships with external stakeholders [26,27]. Little attention has been paid to what is happening inside the firm to see how corporate ethics and MA may translate into employees' performance [28]. This study fills this literature gap by revealing the internal dynamics of a firm and how MA of employees can increase employees' performance. The main objective of the present study was to discover the impact of enhanced MA on the resultant performance of employees. Additionally, the moderation effect of the age, education level and gender of employees was also tested on this relationship.

We tried to test the reliability of the tool for the evaluation of employees' job performance through our pilot study. The scale reliability coefficient 0.72 was obtained for the questionnaire used to evaluate employees' job performance during the pilot study, and it was accepted as such. The results of the empirical analyses support H1 as proposed. This is in line with the idea that employees act as moral agents engaged in EDM as per their prevalent MWEP under a given situation. It is therefore possible to influence EDM by both moral capacity and situational factors, which, as a result, may increase job performance. The research experiment conducted at Lahore Garrison Golf and Country Club specifically endorses the proposed $\mathrm{H} 1$ that enhancing MA through the normative significance of MWEP (i.e., early morning motivational talks) can augment EDM and the resultant performance of employees measured through the response of the clients.

The findings of this study shed light on the understanding of how employees are moved to perform at a better level under the effect of enhanced MA. The study provides important implications for business managers for optimizing the output of their human resource and thereby enhancing organizational competitiveness.

At the end of the experiment, feedback was also provided to the management of Lahore Garrison Golf and Country Club, with a suggestion to apply the MA technique to obtain better performance from employees. The management of the club showed their interest in continuing the activity for a few more months so that it would become a permanent feature of their culture. The experiment was, however, called off because of a shortage of time and resources.

The increasing MA significantly impacted the odds of the highest category of subvariables (except the appearance) of employees' job performance versus all remaining categories, provided that the other variables were the same. The odds of the highest category in the appearance sub-variable versus the combined remaining categories did not significantly change with increasing MA. A qualitative inquiry from the employees after the experiment revealed that the employees considered the emphasis by the club management on appearance as superfluous and that wearing good coveralls has no relevance to morality. One employee went to the extent of saying, "I don't think we will be considered immoral for not wearing the good coverall". The qualitative inquiry also indicated that sub-variables with high odds ratios, such as the quantity and quality of the work and honesty, were important from an MA point of view. This implies that employee intervention should address such factors that are important from an MA point of view. The findings of the study imply that managers may focus on increasing MA of employees to achieve enhanced performance. Interestingly, employee intervention did not impact all the sub-variables of the employees' job performance construct; rather, there was an increase in the output of 
only the sub-variables that are considered important by the employees from an MA point of view.

The results of this experimental study support H1. This is consistent with the findings of past studies, which suggest that firm performance has a strong relationship with the internal dynamics of the firm $[29,30]$. However, H2A, H2B and H2C, which postulated the moderating effect of age, education level and gender on the relationship between MA and employees' performance, were not supported at the desired level of statistical significance. However, they do not show negative signs either. We can therefore say that increased MA will have a uniform impact on all employees' job performance and that a difference in the age, education level or gender of employees does not matter.

Special care was taken to guard against the Hawthorne effect and spillover effect. The experiment was conducted in five phases due to this consideration. The employees did not know that their performance was being evaluated for anything other than the routine. Their involvement was limited to motivation sessions only. It was assumed that the performance of the experiment group may remain unchanged during the first two phases, that it may improve during phase 3 , and that it may come down again during phase 4 and further down during phase 5 (almost equal to phase 1 level). The performance remained unchanged during the first two phases, and it did improve during phase 3 as assumed. The performance came down during phase 4 and further down during phase 5 but not to the phase 1 level. This was due to the residual effect of increased MA, which is likely to persist for some time after increased MA. Regarding the spillover effect, it was assumed that the performance of the control group may have remained unchanged throughout the five phases if there was no spillover effect. This was confirmed to be the case, with the exception of one odd employee. The findings of the empirical analyses succeeded in drawing several useful conclusions. The findings of the empirical analyses support $\mathrm{H} 1$ in that an increased MA will move the employees to a higher level of performance.

As described by institutional theory, macro-organizational phenomenon occurring at the firm level can manifest in micro-level performance, such as employees' attitudes and behaviors [29,31]. Thus, a highly significant positive impact of MA upon employees' output provides a useful implication by suggesting a good tool to the entrepreneurs and business leaders for motivating their employees to exhibit the optimum level of performance even without direct supervision. Business leaders can motivate their subordinates to work more productively by concentrating on increasing their MA and designing jobs along such moral standards. The findings also suggest training managers to be able to emphasize MA of their employees. Management education and training programs may bring in ways of designing jobs with good fit with the employee's moral standards.

\section{Theoretical and Practical Contributions}

The objective of this study was to contribute to the theory of employees' performance by identifying some tools to enhance employees' performance. The study succeeded by providing a model showing the importance of MA to enhance employees' performance. We also identified the importance of the moral training of employees to enhance their MA. Similar to previous research, where the focus was on enriching the job in a variety of ways, we suggest that the managers and leaders should focus on job designing in line with MA of the employees [32]. Designing the job in line with MA of the employees may be more attractive for morally aware employees to use their skills and perform challenging work. Giving workers tasks in line with their MA leads to intrinsic motivation, and, thus, they perform much better as compared to employees with lesser MA and jobs not related to their MA. Thus, the present study adds a greater understanding about which job characteristics may benefit organizations. While some degree of variety in job tasks is probably attractive to most employees, selective optimization with compensation theory and socio-emotional selectivity theory would suggest that task variety in line with their MA is most useful to workers for whom it matches with their MA. Workers, on the other hand, would not benefit as much from simply performing more tasks, as they do not need to be doing more tasks, but 
they would benefit from performing satisfying tasks that allow them to satisfy their moral standards. Indeed, it is becoming critical to understand how to design jobs to keep workers of different ages, gender and educational levels satisfied and engaged in their work [33]. The present study showed that the demographic factors age, gender and educational level did not interact with MA to affect employees performance. These are therefore considered irrelevant, and employees' moral standards improve with moral training irrespective of these demographic factors. On practical grounds, this study contributes by suggesting that organizations may hire employees with high MA, or, alternatively, they can enhance their MA through MA training. The study also pointed out the importance of the role of the managers and business leaders who can train their employees on MA. The companies may hire managers with high MA and an ability to train and enhance MA of their subordinates.

\section{Conclusions}

The MWEP of employees helped in improving our understanding of how increasing MA affected positive behavioral change from avoidance of responsibility toward accepting it among employees. After increased MA, the employees may be expected to perform at a better level even without any direct supervision. Increasing MA can therefore be used as an effective tool to achieve better performance from employees. Managers may be trained to be able to utilize this tool to optimize the performance of their organization. The businesses could therefore select employees who have better MA and try to further enhance it to achieve the optimum output. The importance of this approach has increased manifolds due to the ever increasing breaches of trust in the business world, e.g., the cases of Enron, Tyco and Worldcom, and research is also available that suggests that trust can increase the performance of an organization [34]. There is a need to explore MA as a motivational tool from different angles and at different levels of an organization to know how to make it more effective. These conclusions are applicable across the age, education level and gender of the employees. Hence, we can conclude from the results of this study that increased MA of employees of a firm through employees' attitude and behavior may result in improved performance on part of the employees. The study concluded that increasing MA increases employees' performance with no significant moderation effect of age, gender and education level on this relationship.

\section{Limitations and Future Research Recommendations}

Additional time and resources are needed to increase the effectiveness of the results in such a sophisticated area of study. The idea of enhancing MA for better work performance can be utilized in different types of organizations and cultures to investigate its effectiveness and generalizability. There is also room for further research on the effectiveness of other normally used cognitive reinforcement tools (e.g., daily reading checklists, singing the national anthem and playing music) and to compare it with the effectiveness of increasing MA among employees. The nature of an employee's job and its good match with an employee's moral standards is likely to act as a moderating variable. Future researchers may look into such moderation effects. The difference of impact of increased MA and increased supervision of employees' job performance can be studied in future research. In this study, the phases of the experiment were restricted to one month each due to less time and resources. Researchers may also conduct prolonged experimental research on similar lines in order to ascertain the point when the effect of increase in MA and the resulting increase in employees' job performance will reach the point of diminishing return.

Author Contributions: Conceptualization by M.H. and A.N.; methodology by A.N.; results by Z.I.; validation by H.H. and M.H.; formal analysis by H.H.; investigation by M.H.; resources by Y.H.; writing-original draft preparation by A.N.; writing-review and editing by Y.H. and M.H. All authors have read and agreed to the published version of the manuscript.

Funding: This research is funded by JSPS KAKENHI grant number 18 K01746. 
Institutional Review Board Statement: The study was conducted according to the guidelines of the departmental committee of professional ethics of FAST, School of Management, National University, Lahore, Pakistan.

Informed Consent Statement: Informed consent was obtained from all subjects involved in the study. Data Availability Statement: doi:10.5281/zenodo.4480021.

Acknowledgments: We acknowledge the management of the Lahore Garrison Golf and Country Club for facilitating this study. We also thank veteran golfers, especially Mian Muhammad Farooq, who helped us in conducting the experiment. All the participants of the experimental study deserve our special appreciations for their wholehearted cooperation.

Conflicts of Interest: The authors declare no conflict of interest.

\section{References}

1. Blaug, M.; Spiegel, H.W. The Growth of Economic Thought. Economica 1972, 39, 111. [CrossRef]

2. Chun, J.S.; Shin, Y.; Choi, J.N.; Kim, M.S. How Does Corporate Ethics Contribute to Firm Financial Performance?: The Mediating Role of Collective Organizational Commitment and Organizational Citizenship Behavior. J. Manag. 2013, 39, 853-877. [CrossRef]

3. Diehl, H. Staging Reform, Reforming the Stage; Cornell University Press: Ithaca, NY, USA, 2019. [CrossRef]

4. Ashbrook, R. Mansions of the Heart: Exploring the Seven Stages of Spiritual Growth; John Wiley \& Sons: Hoboken, NJ, USA, 2009.

5. Tawney, R. Religion and the Rise of Capitalism; Transaction Publishers: Piscataway, NJ, USA, 1998.

6. Afsar, B.; Al-Ghazali, B.; Umrani, W. Retracted: Corporate social responsibility, work meaningfulness, and employee engagement: The joint moderating effects of incremental moral belief and moral identity centrality. Corp. Soc. Responsib. Environ. Manag. 2020, 27, 1264-1278. [CrossRef]

7. Weber, M.; The Protestant Ethic and the Spirit of Capitalism. Scribner. 1930. Available online: https://scholar.google. com/scholar?hl=en\&as_sdt=0\%2C5\&q=Weber\%2C+M.+\%281930\%29.+The+Protestant+ethic+and+the+spirit+of + capitalism . + Scribner\%2FSimon+\%26+Schuster.\&btnG= (accessed on 29 August 2021).

8. Zhang, S.; Chen, L.; Yan, J. How protestant work ethic impacts employees' counterproductive work behaviors: The moderating effects of gender and party affiliation. Int. J. Sel. Assess. 2020, 28, 531-540. [CrossRef]

9. Miller, M.J.; Woehr, D.; Hudspethc, N. The meaning and measurement of work ethic: Construction and initial validation of a multidimensional inventory. J. Vocat. Behav. 2002, 60, 451-489. [CrossRef]

10. Woehr, D.J.; Arciniega, L.; Lim, D.H. Examining Work Ethic Across Populations. Educ. Psychol. Meas. 2007, 67, 154-168. [CrossRef]

11. Christians, C.G.; Fackler, M.; Richardson, K.B.; Kreshel, P.J.; Woods, R.H. Media Ethis: Cases and Moral Reasoning; Routledge: London, UK, 2017.

12. Kim, M.J.; Kim, B.J. Analysis of the importance of job insecurity, psychological safety and job satisfaction in the CSR-performance link. Sustainability 2020, 12, 3514. [CrossRef]

13. Richardson, C.; Sinha, L.; Yaapar, S. Work ethics from the Islamic and Hindu traditions: In quest of common ground. J. Manag. Spirit. Relig. 2014, 11, 65-90. [CrossRef]

14. Parker, J. Social Work Practice: Assessment, Planning, Intervention and Review; Sage: Newcastle, UK, 2020.

15. Walker, A.G.; Jones, M.N.; Wuensch, K.L.; Aziz, S.; Cope, J.G. Sanctifying work: Effects on satisfaction, commitment, and intent to leave. Int. J. Psychol. Relig. 2008, 18, 132-145. [CrossRef]

16. Hall, M.E.L.; Oates, K.L.M.; Anderson, T.L.; Willingham, M.M. Calling and conflict: The sanctification of work in working mothers. Psychol. Relig. Spirit. 2012, 4, 71-83. [CrossRef]

17. Loe, T.W.; Ferrell, L.; Mansfield, P. A review of empirical studies assessing ethical decision making in business. J. Bus. Ethics 2000, 25, 185-204. [CrossRef]

18. Kohlberg, L. Essays on Moral Development/2 The Psychology of Moral Development. 1984. Available online: https://ixtheo.de/ Record/1082043133 (accessed on 29 August 2021).

19. Rest, J. Moral Development: Advances in Research and Theory. 1986. Available online: https:/ / repository.library.georgetown. edu/handle/10822/811393 (accessed on 29 August 2021).

20. Rogerson, M.D.; Gottlieb, M.C.; Handelsman, M.M.; Knapp, S.; Younggren, J. Nonrational processes in ethical decision making. Am. Psychol. 2011, 66, 614-623. [CrossRef]

21. Sonenshein, S. The role of construction, intuition, and justification in responding to ethical issues at work: The sensemakingintuition model. Acad. Manag. Rev. 2007, 32, 1022-1040. [CrossRef]

22. Chen, A.; Treviño, L.K.; Humphrey, S.E. Ethical Champions, Emotions, Framing, and Team Ethical Decision Making. J. Appl. Psychol. 2020, 105, 245-273. [CrossRef]

23. Schwartz, M.S. Ethical Decision-Making Theory: An Integrated Approach. J. Bus. Ethics 2015, 139, 755-776. [CrossRef]

24. White, D.W.; Lean, E. The impact of perceived leader integrity on subordinates in a work team environment. J. Bus. Ethics 2008, 81, 765-778. [CrossRef]

25. Chung, J.E.; Park, N.; Wang, H.; Fulk, J.; McLaughlin, M. Age differences in perceptions of online community participation among non-users: An extension of the Technology Acceptance Model. Comput. Hum. Behav. 2010, 26, 1674-1684. [CrossRef] 
26. Porter, C.E.; Donthu, N. Using the technology acceptance model to explain how attitudes determine Internet usage: The role of perceived access barriers and demographics. J. Bus. Res. 2006, 59, 999-1007. [CrossRef]

27. Bruton, G.D.; Ahlstrom, D.; Li, H. Institutional theory and entrepreneurship: Where are we now and where do we need to move in the future? Entrep. Theory Pract. 2010, 34, 421-440. [CrossRef]

28. Whittier, N.C.; Williams, S.; Dewett, T.C. Evaluating ethical decision-making models: A review and application. Soc. Bus. Rev. 2006, 1, 235-247. [CrossRef]

29. Singh, S.K.; Chen, J.; Del Giudice, M.; El-Kassar, A.-N. Environmental ethics, environmental performance, and competitive advantage: Role of environmental training. Technol. Forecast. Soc. Chang. 2019, 146, 203-211. [CrossRef]

30. Lee, W.; Choi, S.; Kang, S.-W. How leaders' positive feedback influences employees' innovative behavior: The mediating role of voice behavior and job autonomy. Sustainability 2021, 13, 1901. [CrossRef]

31. Wang, Y.; Ahmad, W.; Arshad, M.; Yin, H.; Ahmed, B.; Ali, Z. Impact of coordination, psychological safety, and job security on employees' performance: The moderating role of coercive pressure. Sustainability 2021, 13, 3175. [CrossRef]

32. Zacher, H.; Frese, M. Maintaining a focus on opportunities at work: The interplay between age, job complexity, and the use of selection, optimization, and compensation strategies. J. Organ. Behav. 2011, 32, 291-318. [CrossRef]

33. Erdogan, B.; Bauer, T.N.; Truxillo, D.M.; Mansfield, L.R. Whistle While You Work: A Review of the Life Satisfaction Literature. J. Manag. 2012, 38, 1038-1083. [CrossRef]

34. Niazi, A.; Hassan, H. Perception of Justice and Trust in Software Industry of Pakistan. J. Manag. Res. 2017, 4, 39-64. [CrossRef] 